\title{
Weld Overlay Technique using Different Filler Rod Size to Overcome Internal Corrosion of Low Carbon Steel Base Metal
}

\author{
NurAzida CheLah, Muhamad Hellmy Hussin
}

\begin{abstract}
Overlay welding is commonly used to repair and replace the affected corroded surface of the base metal of a component. In other words, it is used to restore the original dimensions of the component. Weld overlay usually applies a corrosion resistant or hard facing layer onto the base metal. This experiment is to determine the suitable filler rod size in repairing corroded low carbon steel (LCS) base metal, respectively to the affected area and to identify the type of distortion occurring on the weldment. It is also to examine the microstructure of the joint between the overlay weld and corroded low carbon steel base metal using SEM/EDX. The overlay welding process was conducted on the corroded samples using SMAW process at defined attacked corroded areas. Filler electrode E-7018 with two diameter sizes of $3.2 \mathrm{~mm}$ and $2.6 \mathrm{~mm}$ were selected. It was found that the bigger electrode size produced higher degree of distortion angle compared to smaller electrode size. Resulting from the metallographic and SEM/EDX analysis, the joint between weld overlay and corroded LCS were fused well without any sign of oxides or other impurities present. Overlay welding also remove the sign of chloride ions that cause the LCS base metal to corrode. Thus, the repairing technique using overlay welding was found successful in repairing corroded LCS base metal. Therefore, the most suitable electrode size to do overlay welding on corroded low carbon steel base metal is $2.6 \mathbf{~ m m}$ diameter electrode.
\end{abstract}

Index Terms: filler electrode, overlay welding, low carbon steel, distortion, SEM/EDX.

\section{INTRODUCTION}

Overlay welding is a technique of using any welding process to repair and replace the surface of the parent metal or to build up the original dimension of the structure or component where one or more metals with specific typical features are applied to a base metal. Weld overlay also can be ascribed as cladding, hard facing, weld cladding or weld overlay cladding [1]. Weld overlay also implement a corrosive resistant or hard facing layer onto the base metal. This is to restore the original dimension of the parent metal as mentioned earlier. In other words, weld overlay technique provides a surface protection or surface resistant which then

\section{Revised Manuscript Received on February 21, 2020.}

* Correspondence Author

NurAzida CheLah*, Fabrication \& Joining, University of Kuala Lumpur Malaysia France Institute (UNIKL MFI), Selangor, Malaysia.

Muhamad Hellmy Hussin, Fabrication \& Joining, University of Kuala Lumpur Malaysia France Institute (UNIKL MFI), Selangor, Malaysia.

(C) The Authors. Published by Blue Eyes Intelligence Engineering and Sciences Publication (BEIESP). This is an open access article under the CC BY-NC-ND license (http://creativecommons.org/licenses/by-nc-nd/4.0/) allows the substrate material to provide strength requirement to allow the equipment to function in a cost effective manner. Weld overlay is commonly used to repair components such as pipes, valves and vessel mostly in oil and gas industries. Shielded Metal Arc Welding (SMAW) are commonly used to perform overlay welding in industries but for some cases other types of welding process can be use such as Gas Metal Arc Welding (GMAW) [2-4]. In oil and gas industries, water wall tubes and fittings are commonly attacked by molten chloride salts and superheat tubes turn up to be attacked by a mixture of molten chloride or sulfate salts as well as gaseous chloride constituents primarily HCL. In this case, pressure vessels are the common structures that are exposed to corrosion. Paul et al. (2004) stated that the corrosion rate of carbon steel due to gaseous chloride atmospheres increases regularly with temperature in various corrosion medium and mechanisms. In other cases, the ingress of chloride ions in cement matrix structure, when the steel is subjected to a low $\mathrm{pH}$, or a pore solution containing chlorides, the passivity of the metal is lost [5]. In this corrosion process, anodic reactions of carbon steel involved in dissolving an iron through many possible reactions, thus the possible compound of iron oxides will form. As well known, the iron oxides are chemical compounds which are composed of iron and oxygen and usually this compound will be formed through the oxidation reaction. As an impact of the failure, the cost of corrosion to the total economy was measured and calculated in millions of dollars each year. In addition to this, carbon steels still exhibit the largest single class of alloys used, both in terms of tonnage and total cost. Thus, it is easy to interpret that the affected corroded carbon steels is a major problem of most of the technological importance [6]. Accordingly, this is the reason why most industries are committed in providing protective or resistant systems for their carbon steel structures. In this manner, corrosion failure will affect the structures and degrades its effectiveness. In repairing work, replacing the whole structures may be costly and caused down time or shutdown during the replacement process. These are the problems that need to be overcome to maintain the structure physical properties and usefulness. There are a few methods to repair the affected corroded part on steel structures such as surfacing welding, hardfacing welding and overlay welding. When doing the overlay welding on a parent metal surface, it is important to make sure that the parent metal with original dimension can be restored and maintained its properties. 
Meanwhile, during this process, a few problem or defects may occur after the overlay welding process such as distortion and changes in microstructures of the base metal. These changes will alter the mechanical properties of the base metal. Distortion will also cause residual stress increases in the base metal structure. Gradually, this will cause the structures or components to fail during service. Additionally, the selection of filler rod size is critical and appear to be an important factor to reduce the time taken and cost caused by the repairing procedure in order to maintain the original properties of the parent metal [6-8]. The selected filler rod must contain specific characteristics to increase the corrosion resistance or wear resistance. High heat input produced by the bigger filler rod will gradually affect the properties of the parent metal and caused distortion. Although the distortion cannot be avoided but it can be minimized by taking some precaution steps [9-12]. On the other hand, other defects such as cracks, undercut, slag inclusion and porosity can also occur. Accordingly, the current paper presents the comparison of different filler rod size used to perform an overlay welding technique as a repairing method on corroded part of low carbon steel. The microstructure and cross section analysis of the joint between the weld overlay and the base metal part were elucidated using SEM and EDX analysis.

\section{MATERIALS AND METHODS}

\section{A. Material Preparation}

In conjunction to high application in industries, welding samples were prepared using low carbon steel (LCS) plates. This type of metal contains less than $0.3 \%$ carbon. It is alloyed with magnesium and very small amounts of sulphur to improve the hardenability and make the carbon steel malleable and strong at high temperature. The composition analysis was carried out using Spectrometer Arc SpectroMax testing machine for both base metal and filler electrode. The composition of LCS is shown in Table 1.

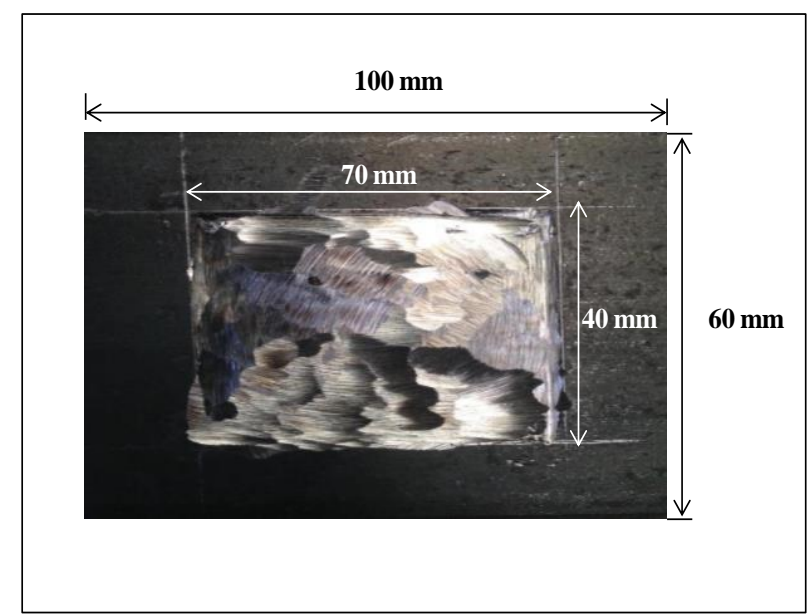

Fig. 1. Corroded region of unwelded sample

The LCS plates were cut according to the size of $100 \mathrm{~mm} \mathrm{x}$ $60 \mathrm{~mm}$ x $12 \mathrm{~mm}$ as shown in Figure 1. Twelve (12) samples were prepared for each parameter. To obtain metal plate with corrosion region on top of the plate, the plate must undergo grinding process to create a puddle area. The size of the puddle is $60 \mathrm{~mm} \times 40 \mathrm{~mm}$ in dimension and about $2 \mathrm{~mm}$ depth as shown in Figure 1. Solution used to corrode the LCS base metal is hydrochloric acid (HCL) with 6 mol concentration. High concentrated acid needed to accelerate the corrosion rate of the base metal. Acid solution was poured in the created base metal puddle and was left for 5 days. The corroded sample is shown in Fig. 1. The corroded affected area in the LCS base metal puddle was observed to make sure that it is enough and suitable for repairing process. Then, the sample was cleaned and brushed to remove the surface oxide before conducting overlay welding process.

Table 1.Element compositions in wt \% of low carbon steel

\begin{tabular}{|c|l|l|l|l|l|l|}
\hline $\mathbf{C}$ & Si & S & Cu & Mn & P & Fe \\
\hline 0.29 & 0.28 & 0.05 & 0.20 & 1.03 & 0.04 & 98.0 \\
\hline
\end{tabular}

\section{B. Welding Parameters and Visual Inspection}

Table 2 shows the welding parameters used in overlay welding technique. All the samples were welded by using the same parameter but different diameter size of the filler electrode. The preferred welding process is Shielded Metal Arc Welding (SMAW) technique due to its simple and versatile usage. SMAW process is often used in overlay welding in heavy industry application. Position used in this welding process is $1 \mathrm{G}$ position. In order to minimize weld distortion, before welding operation, the samples were located in the fixture jig. The defects expected from this process are slag inclusion, undercut and distortion.

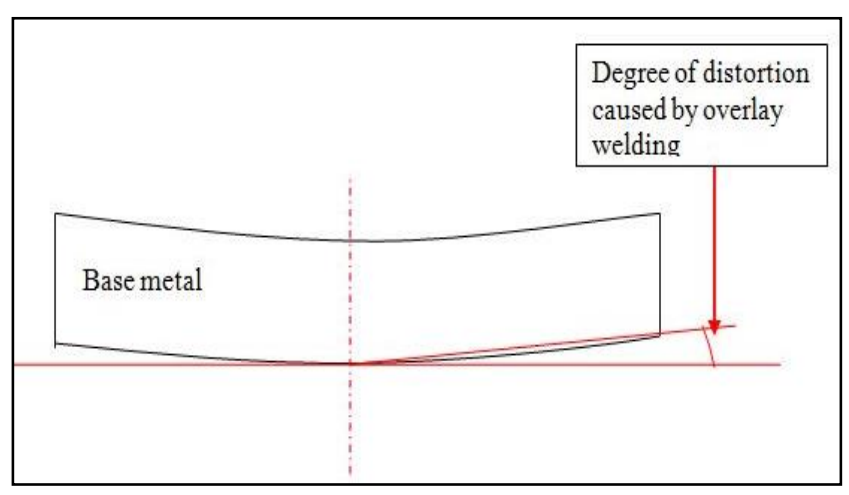

Fig.2. Diagram of distortion measurement

Table 2.Welding parameters used to performe overlay welding technique on samples $A$ and $B$.

\begin{tabular}{|l|c|c|}
\hline \multirow{2}{*}{ Welding Parameter } & \multicolumn{2}{c|}{ Description } \\
\cline { 2 - 3 } & Sample A & Sample B \\
\hline Diameter of filler rod & $3.2 \mathrm{~mm}$ & $2.6 \mathrm{~mm}$ \\
\hline Amperage & $90-140 \mathrm{~A}$ & $90-140 \mathrm{~A}$ \\
\hline Voltage & $80-110 \mathrm{~V}$ & $80-110 \mathrm{~V}$ \\
\hline Electrode type & E-7018 & E-7018 \\
\hline
\end{tabular}


Table 3.Element compositions in wt\% of filler metal electrode E-7018.

\begin{tabular}{|c|c|c|c|c|c|c|c|c|c|}
\hline $\mathbf{C}$ & $\mathbf{S i}$ & $\mathbf{S}$ & $\mathbf{M n}$ & $\mathbf{P}$ & $\mathbf{N i}$ & $\mathbf{C r}$ & $\mathbf{M o}$ & $\mathbf{V}$ & $\mathbf{F e}$ \\
\hline 0.15 & 0.75 & 0.035 & 1.60 & 0.035 & 0.30 & 0.20 & 0.30 & 0.08 & 96.5 \\
\hline
\end{tabular}
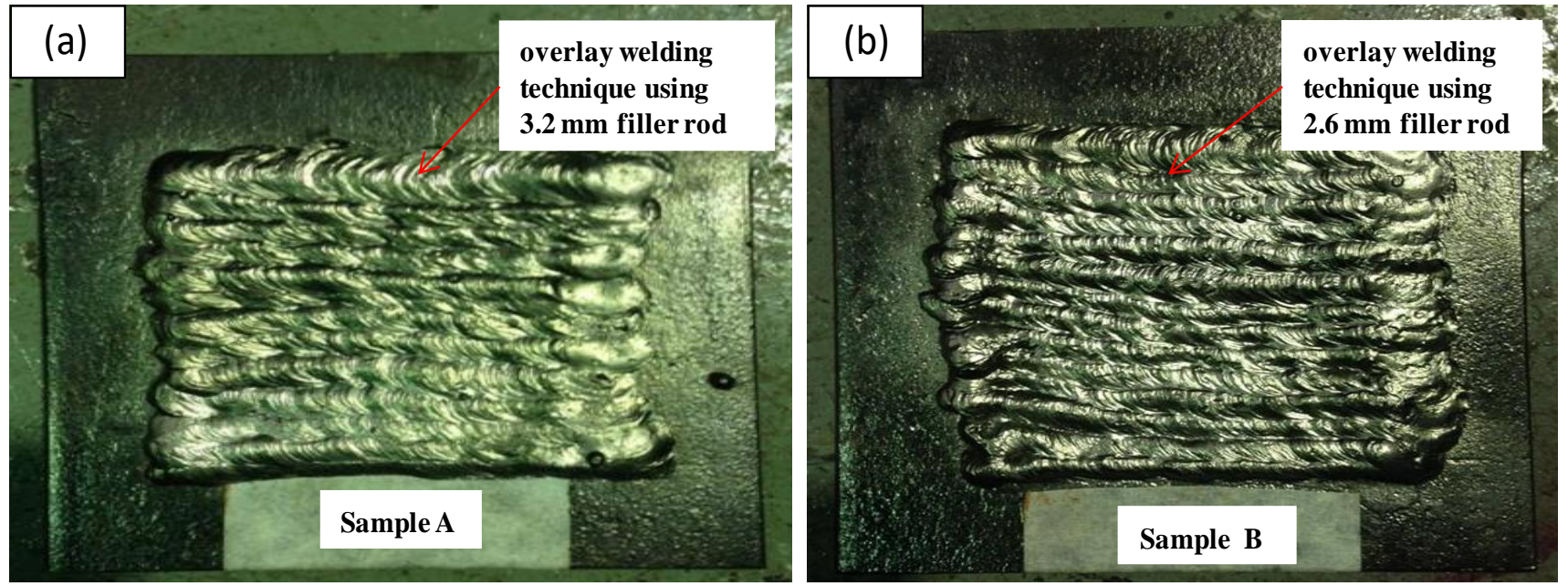

Fig. 3.Overlay welding technique performed on corroded base metal using (a) $3.2 \mathrm{~mm}$ and (b) $2.6 \mathrm{~mm}$ diameter welding electrode.

Table 3 shows the composition of filler electrode E-7018. This type of filler electrode is usually used in all position of low hydrogen iron powder electrode. Normally, it is used to weld a variety of carbon and low alloy steels that require the characteristics of impact toughness especially at low temperatures. In principal, the welding filler electrode selection was based on the mechanical properties and physical characteristics of the LCS base metal. In this study, two diameter sizes of electrode were selected which are 3.2 $\mathrm{mm}$ and $2.6 \mathrm{~mm}$.After corrosion process, the samples were repaired and welded using overlay technique. Figure 2(a) shows an overlay welded joint performed on sample A. Sample A was welded with 11 weld passes to cover the corroded region using $3.2 \mathrm{~mm}$ diameter electrode. Meanwhile, sample B was welded with 14 weld passes to cover the entire corroded region using $2.6 \mathrm{~mm}$ diameter electrode as shown in Figure 2(b). Time taken to finish the overlay welding process was recorded using stop watch. Next, for visual inspection, Figure 3 shows the diagram on how the degrees of the distortion been measured.

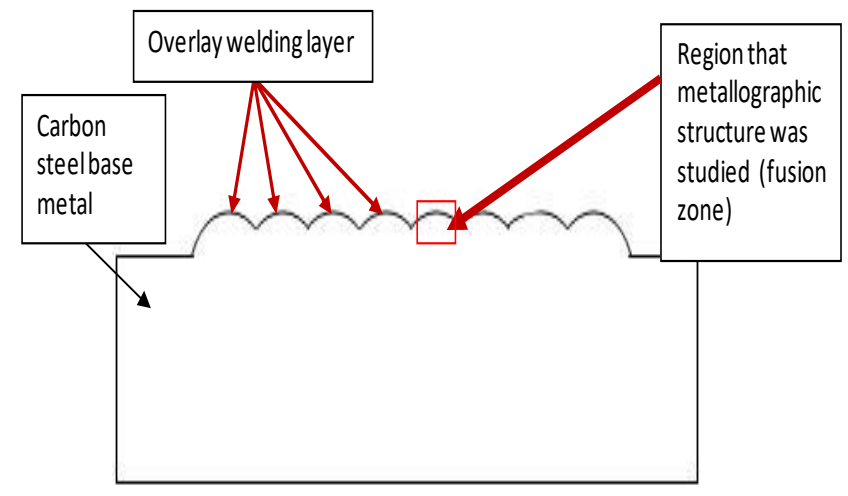

Fig. 4. Diagram of specific region for metallographic analysis

Published By:

\section{A. Metallographic and Composition Analysis of Corroded Samples}

Exposing a base metal part of LCS to HCL acid environments results in growth of an oxide scale. Figure 5 shows a micrograph of SEM images and EDX spectrums of corroded LCS base metal. Figure 5(a) shows a selected of SEM micrograph at higher magnification, presents an accumulation of black oxide residue at point 1 , after exposing to HCL environment. Black oxide crystals have been identified by EDX spectrum in Figure 5 (b) shows that the spectrum peak 1 in SEM image (Figure 5(a)) contained strong two peaks, which were assigned to $\mathrm{Fe}$ and $\mathrm{O}$. As predicted, the peaks around 0.8 and $6.3 \mathrm{keV}$ are referred to the binding energies of $\mathrm{Fe}$. The peak of $\mathrm{O}$ shows the existence of oxide compounds on the surface of the sample and the possible related oxide compound is Fe-rich oxides. Meanwhile, the bright and smooth areas at point 2 and 3 in Figures 5(b) and (c) also show the presence of strong Fe and O peaks. In Figure 5(d), at point 4, the presence of strong peaks of $\mathrm{Fe}, \mathrm{O}$, and $\mathrm{Cl}$. It is confirmed that the sign of $\mathrm{Cl}$ peak shows the possible influence of chloride ions on the sample.

The presence of iron in chloride solution is due to the dissolution of the LCS surface by the aggressive chloride ions attack.

Blue Eyes Intelligence Engineering \& Sciences Publication

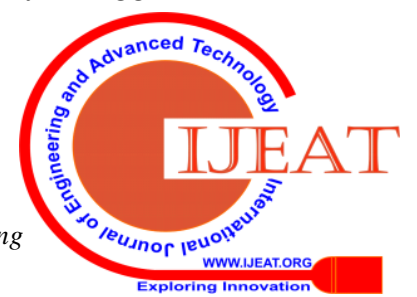




\section{B. Welding Time Taken and Distortion}

Welding time result from sample A and B are shown in Figure 6. Time taken to finish overlay welding on corroded carbon steel base metal with surface area of $49 \mathrm{~mm}^{2}$ by using $3.2 \mathrm{~mm}$ diameter electrode is 270 seconds and for $2.6 \mathrm{~mm}$ diameter electrode is 346 seconds. During welding, usually the distortion occurred in a weld results from the expansion and contraction of the weld metal and adjacent base metal experienced during the heating and cooling cycle of the welding process. The shrinkage and distortion occurring during the welding process will alter the mechanical and physical properties of the weld areas. For example, as the temperature of the weld area increases, yield strength, elasticity, and thermal conductivity of the steel plate decrease, while thermal expansion and specific heat increase.
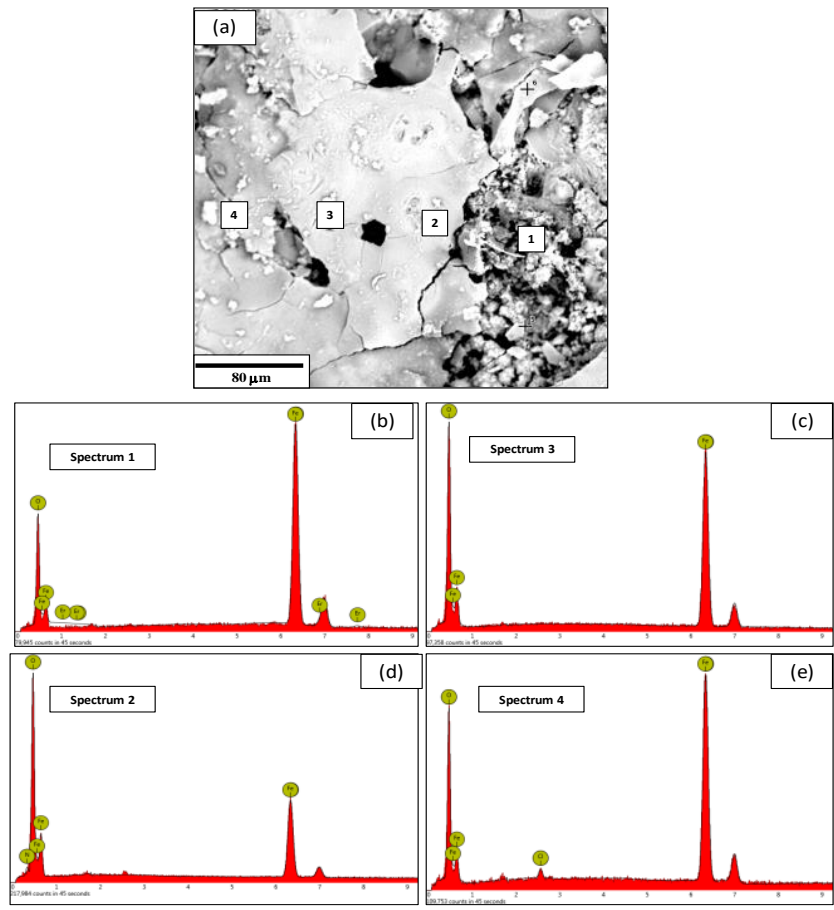

Fig. 5.(a) SEM image of oxidized base metal LCS before performing overlay welding technique, and the EDX spectrum of respective points showing in (b), (c), (d), and (e)
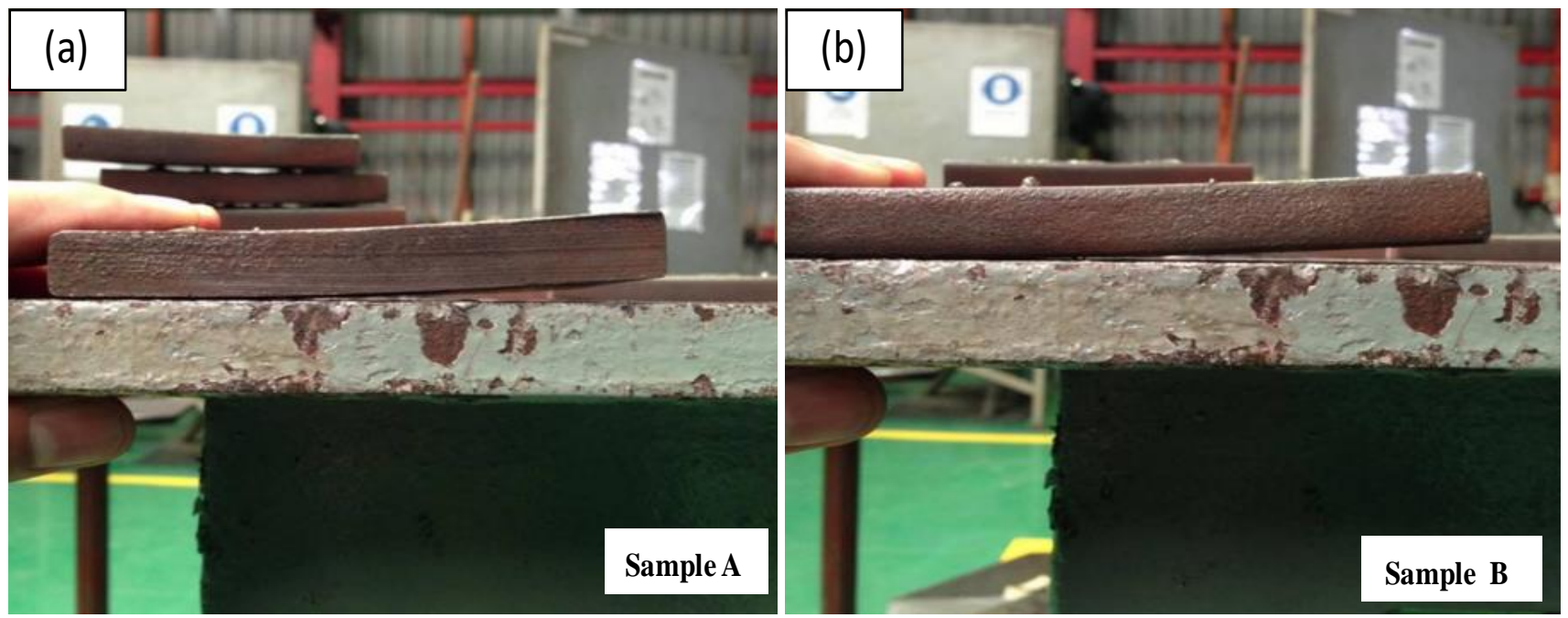

Fig. 7. Distortion on both overlay welded samples, (a) sample A and (b) sample B

Figure 7 show samples A and B were visually inspected to identify the type of distortion occurred. Each samples were inspected thoroughly to identify the distortion occurring.

Resulting from the overlay welding, longitudinal distortion occurred in all samples. Distortion obtained during overlay welding process showed an average measurement of $20^{\circ}$ for sample A, while the average of $17^{\circ}$ was recorded for sample B. Figure 8 shows the histogram diagram of distortion degree comparison for both samples after performing overlay welding technique.

This indicated that bigger electrode size which refers to 3.2 diameter electrode created bigger weld bead size and it shows that less time taken to complete the overlay welding process.

\section{Published By:}

Blue Eyes Intelligence Engineering \& Sciences Publication

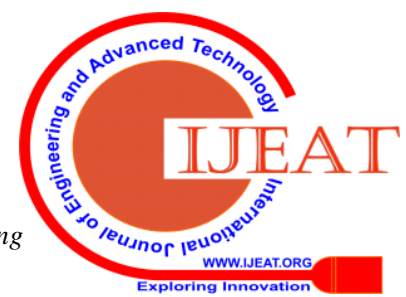


It also produced higher degree of distortion angle compared to smaller electrode size which refers to 2.6 diameter electrode. This is related to the heat accumulated due to bigger size of weld bead because of higher heat input during overlay welding work.

Heat dissipation area becomes wider and leads to the increase of distortion angle. Thus, it shows that bigger electrode size requires higher heat input and dissipation, and produced higher degree of distortion angle. Although, the occurrence of distortion happened during welding using 3.2 diameter filler rod, it is still in the accepted range of angular distortion since all the precautions were applied during performing the welding work.Although the distortion occurred on both of the samples, still the distortion can be neglected because the focus of the work is only on the repairing method on corrosion attacked area. In repairing work, the distortion occurred is not to be counted or can be neglected.

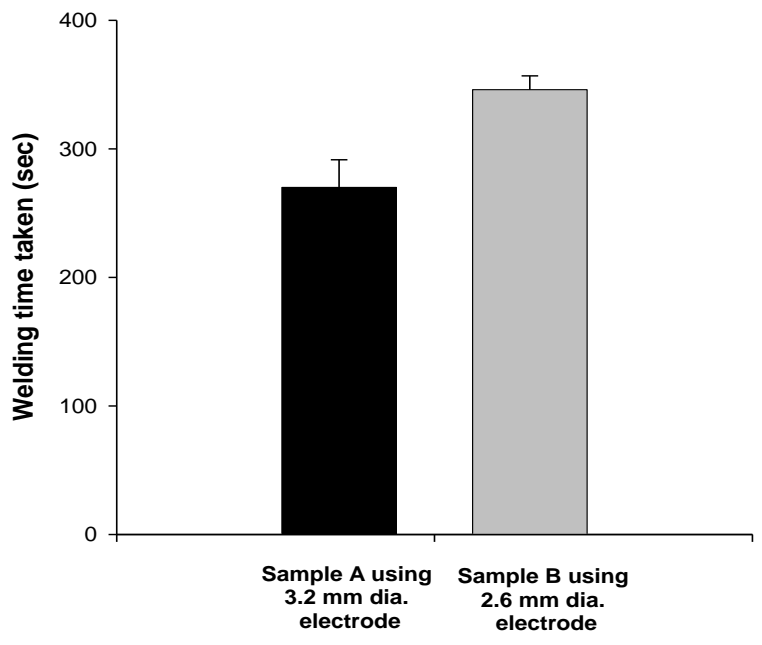

Fig. 6. Welding time taken for sample A and B using different size of electrode

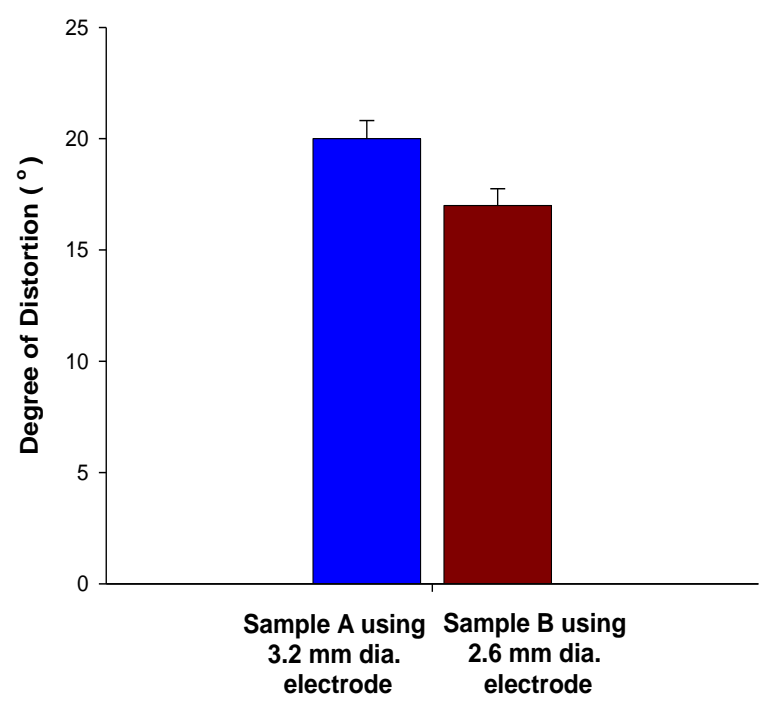

Fig. 8. Distortion occurred on both samples, (a) sample A using $3.2 \mathrm{~mm}$, and (b) sample B using $2.6 \mathrm{~mm}$ diameter electrode

\section{Metallographic and Composition Analysis of Repaired Overlay Welded Samples}

Figures 9 and 110 show the spots where SEM/EDX analysis was scanned on sample A (3.2 mm dia.) and sample B (2.6 mm dia.) filler electrodes respectively. There were three different spectrum spots for each sample where the analyses were conducted on fusion zone of the welded base metal after repairing using overlay welding technique. Both samples indicated that the strongest peak shows the existence of Fe and Mn. Both of the peaks seem to be overlapped with each other and as expected the binding energies of both $\mathrm{Fe}$ and $\mathrm{Mn}$ are approximately 6.0 to $6.3 \mathrm{keV}$. All the three spectrums show the same trend of spectrum peaks.

As indicated in Figs.9 and 10, there is no sign of $\mathrm{Cl}$ peak on both samples after repairing process. It is confirmed that there is no influence of chloride ions on both samples. This indicates that the corrosion defects diminished after repairing process. Thus, the repairing technique using overlay welding was found successful in repairing corroded LCS base metal.

\section{CONCLUSION}

Based on the data collected from the welding time taken, it is obviously stated that by using $3.2 \mathrm{~mm}$ electrode size (sample A), the time taken to finish overlay welding on the corroded LCS base metal are shorter compared to the time taken of sample B using 2.6 mm electrode size.

This indicated that bigger electrode size produce higher degree of distortion angle compared to smaller electrode size. This is related with the heat dissipation to the entire sample surface area. It shows that bigger size electrode requires higher heat input and dissipation, thus produced higher degree of distortion angle.

Resulting from the metallographic and SEM/EDX analysis, the joint between weld overlay and corroded LCS were fused well without any sign of oxides presence or other impurities. Overlay welding also remove the sign of chloride ions that cause the LCS base metal to corrode. 
Weld Overlay Technique using Different Filler Rod Size to Overcome Internal Corrosion of Low Carbon Steel Base Metal

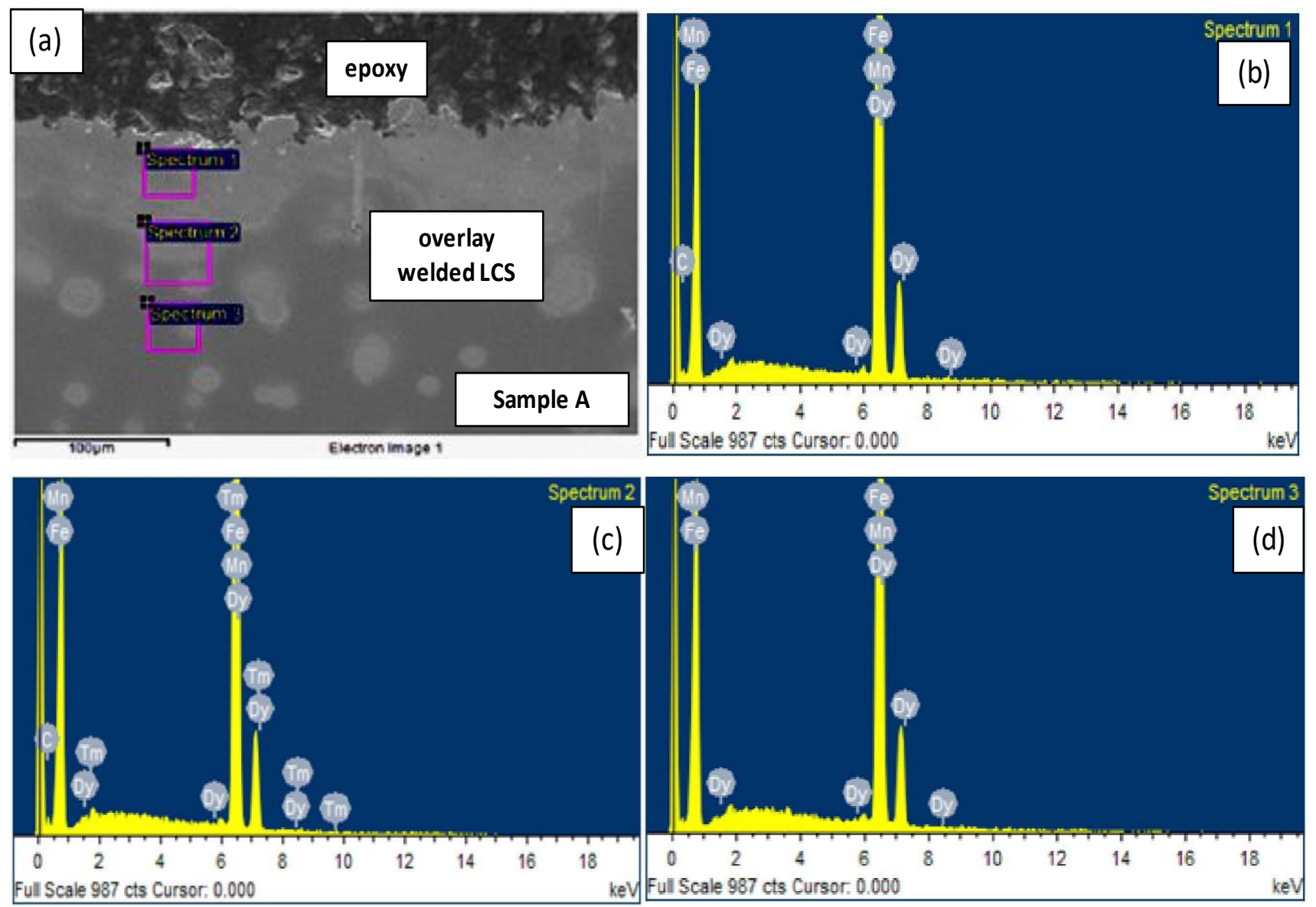

Fig. 9. SEM cross sectional image of repaired overlaywelded LCS (sample A) using $3.2 \mathrm{~mm}$ dia., and theEDX spectrum of respectivepoints showing in (b), (c), and (d)

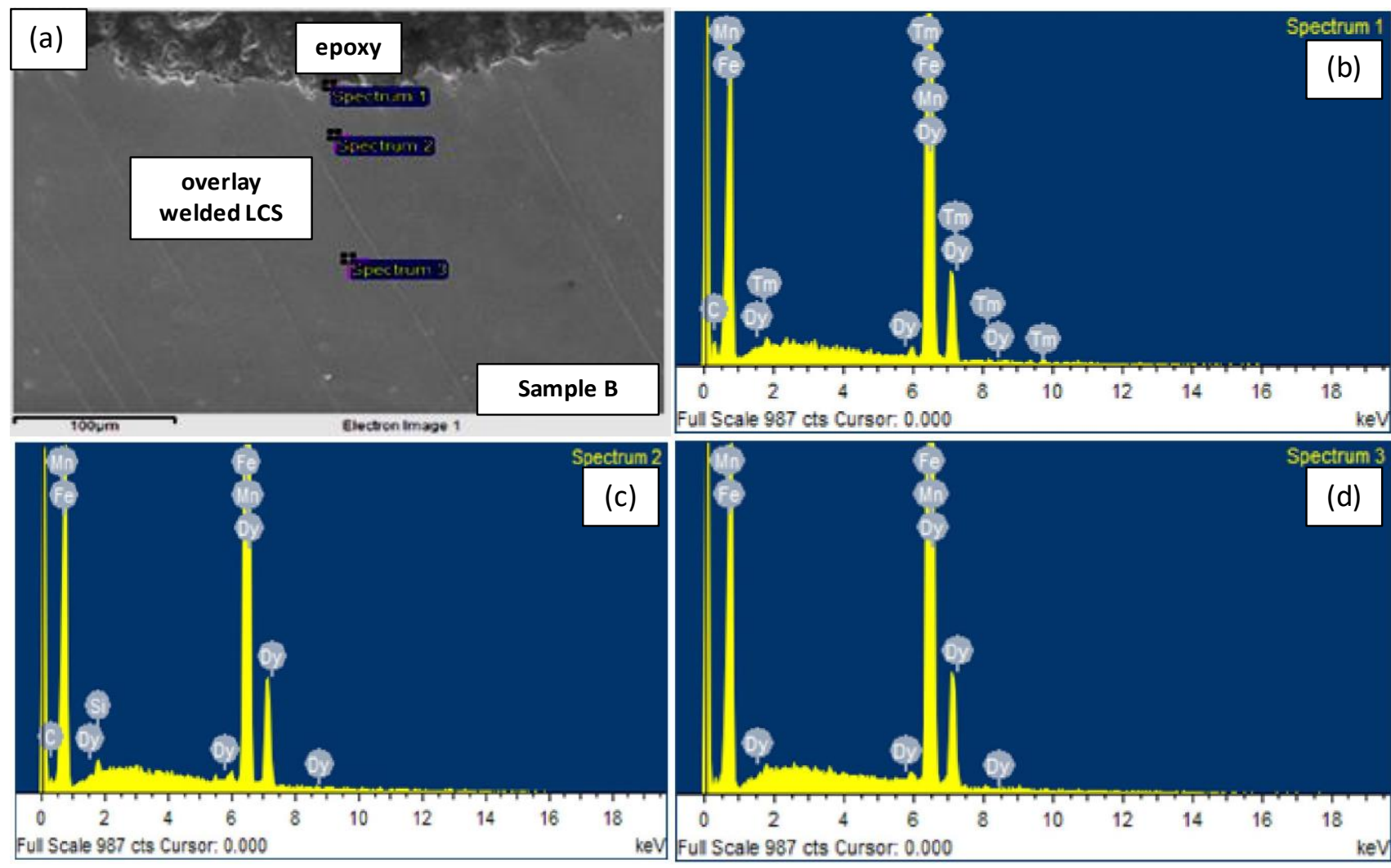

Fig. 10. SEM cross sectional image of repaired overlay welded LCS (sample B) using $2.6 \mathrm{~mm}$ dia., and the EDX spectrum of respective points showing in (b), (c), and (d)

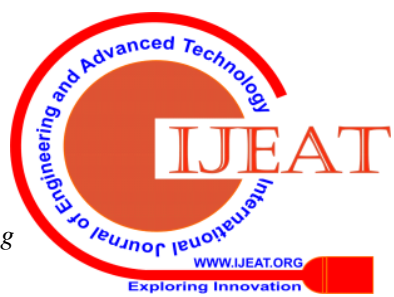




\section{REFERENCES}

1. Lai, G., "Unifuse overlay cladding for surface protection against corrosion and erosion/corrosion in power boilers and waste heat recovery system”, Overlay Cladding in Power Boiler, Vol. 3, (2004), $1-19$.

2. Ursula, H. L., "Hydrochloric acid: Corrosion under control", Sulzer Technical Review, Vol. 4, (2000), 34-37.

3. Finsgar, M. and Jackson, J., "Application of corrosion inhibitors for stellmin acidic media for the oil and gas industry: A review", Corrosion Science, Vol. 86, (2014), 14-41.

4. Lei, Y. and Zheng, Z. P., "Review of physical monitoring techniques for condition assessment of corrosion in reinforced concrete", Math Problem In Engineering, (2013), 1-14.

5. Beal, J. H. L., Prabakar, S., Gaston, N., The, G. B., Echegoin, P. G., William, and Tilley, R. D., "Synthesis and comparison of the magnetic properties of iron sulphide spinel and iron oxides spine", Nanocrystal, Vol. 23, (2011), 2514-2517.

6. Efird, K. D., "The synergistic effect of $\mathrm{Na}$ and $\mathrm{Fe}$ on the sea water corrosion of copper alloys", KD Synergy Information System, Vol. 33 , (1977), 347-350.

7. Tang, J., Shao, Y., Zhang, T., Meng, G., and Wang, F., "Corrosion behavior of carbon steel in different concentrations of HCL solutions containing H2S at 90 oC", Corrosion Science, Vol. 53, (2011), 1715-1723.

8. Joon-Suk Kim and Hae-Woo Lee, "A study on effect of intergranular corrosion by heat input on Inconel 625 overlay weld metal", International Journal of Electrochemical Sciences, Vol. 10, (2015), 6454-6464.

9. Kahar, S. D., and Baba Pai, K., "Corrosion behavior of electro-slag strip cladded weld overlays in different acid solutions", International Journal of Engineering Research and Application, Vol. 3, No. 4, (2013), 2620-2627.

10. Paul, L., Clark, G., Eckhardt, M., and Hoberg, B., "Experience with weld overlay and solid alloy tubing materials in waste to energy plants", 12th North American Waste to Energy Conference, ASME, (2004), 111-119.

11. Elango, P., and Balaguru, S., "Welding parameters for Inconel 625 overlay on carbon steel using GMAW", Indian Journal of Science and Technology, Vol. 8, No. 31, (2015), 1-5.

12. Farkade, N. V. and Ravanan, P. M., "Modification in weld overlay for productivity and corrosion ressitance", International Journal of Science and Technology \& Engineering, Vol. 2, No. 2, (2015), 37-41.

\section{AUTHORS PROFILE}

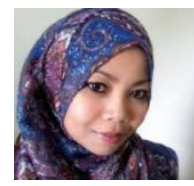

Dr. NurAzida CheLah, is a senior lecturer at the University of Kuala Lumpur Malaysia France Institute (UNIKL MFI), Bandar BaruBangi, Selangor. She did her Bac (Hons) in Materials Science and then pursued her Master degree in Mechanical Engineering majoring in Fatigue failure Assessment on welded joint at University of Putra Malaysia (UPM) Serdang, Selangor. Her PhD focusing on High Temperature Corrosion Study on Aluminium Welded Joint at The National University of Malaysia (UKM), Bangi, Selangor. And since 2007 she started writing an articles and journals mostly on Fatigue Assessment Analysis, Welding and Joining, Corrosion degradation and Failure Analysis Studies.

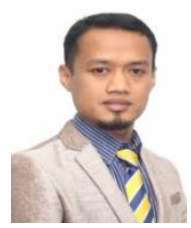

Muhamad Hellmy Hussin, is a lecturer in University of Kuala Lumpur Malaysia France Institute (UNIKL MFI) located at Bandar BaruBangi, Selangor for fourteen years. His expertise is in Innovation and Engineering Design, and also in Corrosion and Failure Analysis. He did his Bac. (Hons.) in Industrial Production Management at the University Nice Sophie Antipolis (UNSA), France, and then pursued his Master Degree in Innovation and Engineering Design at University of Putra Malaysia (UPM) Serdang, Selangor. Over the last eight years he becomes involved in welding and joining research works. And since then he has continued his research and involved in Corrosion and Failure Analysis research areas, Corrosion and failure analysis works. Now, he pursue his PhD in (Mechanical), focusing on High Temperature Corrosion in Hot Gases Environment. He has published articles and journals mainly in Welding and Joining, Corrosion degradation and Failure Analysis research works. 